\title{
Kajian Batasan Nilai Faktor Air Semen pada Campuran Beton di Lingkungan Korosif
}

\author{
NIZAR FARHAN RULIAN, PRIYANTO SAELAN
}

\author{
Program Studi Teknik Sipil, Institut Teknologi Nasional Bandung \\ Email: distorttion@gmail.com
}

\begin{abstract}
ABSTRAK
Beton adalah material konstruksi yang pada saat ini sudah sangat umum digunakan. Saat ini berbagai bangunan sudah menggunakan material dari beton. Pentingnya peranan konstruksi beton menuntut suatu kualitas beton yang memadai, beton tidak hanya digunakan di darat melainkan dapat digunakan juga di dalam air laut. Beton yang berada pada lingkungan korosif atau beton yang terendam air laut nilai faktor air-semennya dibatasi oleh SNI. Nilai maksimum faktor air-semen pada lingkungan air laut yaitu sebesar 0,45. Tujuan penelitian ini adalah untuk mengetahui apakah nilai faktor air-semen masih dapat diperbesar lagi melebihi batas maksimal menurut SNI sesuai dengan kekuatan dan ketahanan yang dapat digunakan pada beton yang terendam air laut. Metodologi ini adalah dengan mengumpulkan data sekunder tentang pengaruh faktor air-semen pada beton yang dirawat menggunakan air laut. Penelitian ini memprediksikan permeabilitas yang berada pada air laut dengan variasi faktor air-semen yaitu sebesar 0,40; 0,50; dan 0,60. Kesimpulan penelitian ini adalah faktor air-semen dapat diperbesar sampai dengan 0,50 apabila umur rencana bangunan 50 tahun.
\end{abstract}

Kata kunci: beton, permeabilitas, faktor air semen

\begin{abstract}
Concrete is a construction material that is currently very commonly used. Nowadays, various buildings are using materials from concrete. The important role of concrete construction demands an adequate quality of concrete, concrete is not only used on land but can also be used in sea water. Concrete that is in a corrosive environment or concrete submerged in seawater, the water-cement factor value is limited by SNI, the maximum value of the water-cement factor in the seawater environment is 0.45 . The purpose of this study was to determine whether the water-cement factor value could still be enlarged beyond the maximum limit according to SNI, which is 0.45 , of course with the strength and resistance that can be used in concrete submerged in sea water. This methodology is to collect secondary data on the effect of the water-cement factor on the concrete treated using sea water. This research predicts the permeability in seawater with variations in the water-cement factor, namely 0.40, 0.50, and 0.60. The conclusion of this study is the water-cement factor can be enlarged up to 0.50 if the age of the building plan is 50 years.
\end{abstract}

Keywords: concrete, permeability, cement water factor 


\section{PENDAHULUAN}

Saat ini beton merupakan bahan konstruksi yang sudah sangat umum digunakan. Berbagai konstruksi bangunan sudah menggunakan bahan dari beton. Beton memiliki peranan penting dalam bidang konstruksi sehingga kualitas beton harus memadai. Adapun kelebihan beton sebagai bahan konstruksi dibandingkan material lainnya antara lain memiliki kuat tekan yang tinggi, mampu mengikuti bentuk bangunan secara bebas, tahan terhadap api, dan biaya perawatan yang relatif murah.

Chlorida menyebabkan korosi pada tulangan sedangkan magnesium sulfat menyebabkan beton kehilangan sebagian massa, kekuatan dan kekakuannya serta mempercepat proses pelapukan. Oleh karena itu, beton yang berada pada lingkungan agresif, harus memiliki ketahanan (durabilitas) yang baik agar umur bangunan yang dirancang dapat dipertahankan.

Di antara parameter ketahanan (durabilitas) adalah permeabilitas dan kedalaman absorbsi. Besarnya permeabilitas dan absorbsi sangat ditentukan faktor air-semen. Semakin besar nilai faktor air-semen maka semakin tinggi nilai permeabilitas dan absorbs. Hal ini dikarenakan semakin tinggi nilai faktor air-semen maka kadar semen semakin rendah sehingga ketahanan beton semakin rendah. Oleh karena itu, faktor air-semen sebaiknya dibatasi nilai maksimumnya agar beton memiliki ketahanan yang baik. SNI 03-2384-2000 membatasi nilai faktor air-semen pada lingkungan agresif yaitu sebesar 0,45.

\section{TINJAUAN PUSTAKA}

\subsection{Pengaruh Air Laut Terhadap Kekuatan dan Ketahanan Beton}

Menurut Wedhanto, S. (2017), pengaruh kimia air laut terhadap beton terutama disebabkan oleh serangan Magnesium Sulfat $\left(\mathrm{MgSO}_{4}\right)$. Hal ini dikarenakan adanya kandungan chlorida di dalamnya, sehingga reaksinya akan menghambat perkembangan beton. Hal ini juga akan mengakibatkan beton tampak menjadi keputih-putihan, lalu beton akan mengembang dengan sebelumnya didahului oleh terjadinya spalling retak. Bagian beton yang terserang oleh sulfat akan menjadi lunak dan membentuk lapisan seperti lumpur.

Serangan Magnesium Sulfat $\left(\mathrm{MgSO}_{4}\right)$ perlu mendapat perhatian, karena jika berekasi dengan Calcium Sulfat (CSH) maka akan bersifat ambivalen. Akan tetapi kekuatan reaksinya menghasilkan gypsum yang sifatnya menguntungkan semen karena tidak memiliki kemampuan rekat. Tabel $\mathbf{1}$ dan Tabel $\mathbf{2}$ menyajikan perkiraan komposisi senyawa dan kadar ion yang terkandung dalam air laut.

Tabel 1. Komposisi Senyawa dalam Air Laut

\begin{tabular}{ccc} 
No. & Senyawa & [gr] \\
\hline 1 & $\mathrm{Fe}_{2} \mathrm{O}_{3}$ & 0,003 \\
\hline 2 & $\mathrm{CaCO}_{3}$ & 0,1172 \\
\hline 3 & $\mathrm{CaSO}_{4} .2 \mathrm{H}_{2} \mathrm{O}$ & 1,7488 \\
\hline 4 & $\mathrm{NaCl}$ & 29,6959 \\
\hline 5 & $\mathrm{MgSO}_{4}$ & 2,4787 \\
\hline 6 & $\mathrm{MgCl}_{2}$ & 3,3172 \\
\hline 7 & $\mathrm{NaBr}$ & 0,5524 \\
\hline 8 & $\mathrm{KCl}$ & 0,5339 \\
\hline & Total & 38,44471 \\
\hline
\end{tabular}


Tabel 2. Kadar Ion dalam Air Laut

\begin{tabular}{ccc}
\hline Nama Umum & Ion & [gr] \\
\hline Sodium & $\mathrm{Na}$ & 10,360 \\
\hline Magnesium & $\mathrm{Mg}++$ & 1,294 \\
\hline Calcium, & $\mathrm{Ca}++$ & 0,413 \\
\hline Potassium & $\mathrm{K}+$ & 0,387 \\
\hline Strontium & $\mathrm{Sr}++$ & 0,008 \\
\hline Clorida & $\mathrm{CL}-$ & 19,353 \\
\hline Sulfat & $\mathrm{SO}_{4}{ }^{2-}$ & 2,712 \\
\hline Bromide & $\mathrm{Br}^{-}$ & 0,008 \\
\hline Boron & $\mathrm{B}$ & 0,001 \\
\hline Bikarbonat & $\mathrm{NaHCO}$ & 0,142 \\
\hline Fluor & $\mathrm{FN} 3$ & 0,001
\end{tabular}

(Sumber: Emmanuel, A. 0., 2012)

\subsection{Persyaratan Beton pada Lingkungan Agresif}

Persyaratan beton menurut ketentuan SNI 02-2834-2000 dapat dilihat pada Tabel 3.

Tabel 3. Ketentuan Minimum untuk Beton Bertulang Kedap Air

\begin{tabular}{|c|c|c|c|c|}
\hline \multirow{3}{*}{ Jenis Beton } & \multirow{3}{*}{ Kondisi Lingkungan } & \multirow{3}{*}{$\begin{array}{c}\text { Faktor Air Semen } \\
\text { Maksimum }\end{array}$} & \multicolumn{2}{|c|}{ Kandungan Semen Maksimum } \\
\hline & & & \multicolumn{2}{|c|}{ Ukuran Nominal Maksimum Agregat } \\
\hline & & & $40 \mathrm{~mm}$ & $20 \mathrm{~mm}$ \\
\hline \multirow{2}{*}{ Beton Bertulang } & Air Tawar & 0,5 & 360 & 290 \\
\hline & Air Laut & 0,45 & 320 & 360 \\
\hline \multirow{2}{*}{ Beton Pratekan } & Air Tawar & 0,5 & 300 & 300 \\
\hline & Air Laut & 0,45 & 320 & 360 \\
\hline
\end{tabular}

\subsection{Faktor Air Semen Pada Campuran Beton}

Semakin tinggi nilai faktor air-semen (FAS) maka kekuatan beton mengalami penurunan. Akan tetapi semakin rendah nilai FAS maka kekuatan beton tidak selalu mengalami peningkatan. Semakin rendahnya nilai FAS juga biasanya beton akan semakin sulit untuk dipadatkan. Oleh karena itu, nilai FAS yang optimal akan mampu menghasilkan kekuatan tekan beton yang maksimal. Menurut Tjokrodimulyo, K. (2007) nilai FAS yang digunakan dalam perancangan campuran beton minimal 0,4 dan maksimal 0,65.

Pengaruh faktor air semen selain berpengaruh terhadap kekuatan juga berpengaruh terhadap ketahanan porositas dan permeabilitas. Gambar 1 merupakan grafik hubungan antara faktor air-semen dengan permeabilitas, terlihat bahwa peningkatan nilai faktor air-semen mengakibatkan nilai permeabilitasnya juga mengalami peningkatan. Dengan demikian, dapat disimpulkan bahwa faktor air-semen mempengaruhi permeabilitas pada beton. Maka, diperlukan penelitian untuk membuktikan nilai faktor air-semen untuk campuran beton yang berada pada lingkungan agresif dapat dikembangkan lagi agar lebih besar. Hal ini dilakukan supaya beton mampu memiliki ketahanan yang baik. 


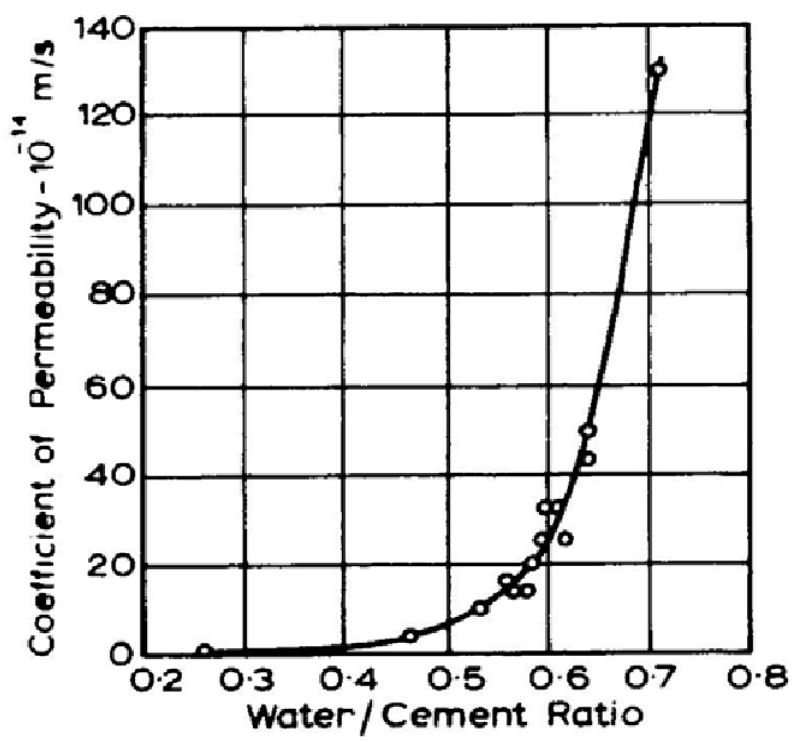

Gambar 1. Grafik Hubungan Antara Faktor Air-Semen dengan Permeabilitas

(Sumber: Zhao, Y., et al., 2014)

\section{METODE PENELITIAN}

\subsection{Diagram Alir}

Diagram alir dalam penelitian ini dibuat untuk memudahkan dalam penyusunan alur kegiatan yang akan dilakukan, seperti terlihat pada Gambar $\mathbf{2}$.

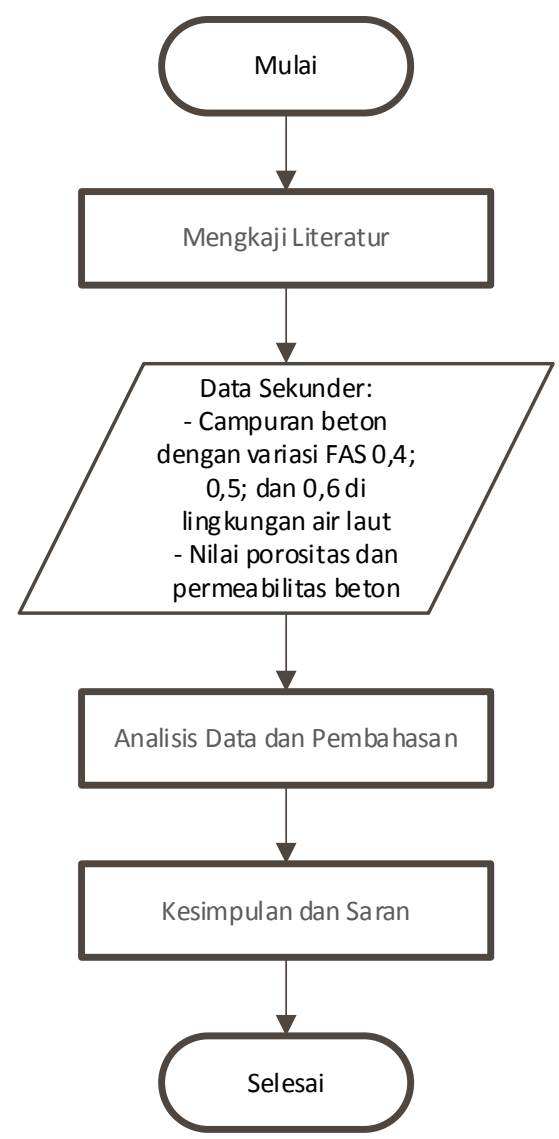

Gambar 2. Diagram alir penelitian 


\subsection{Pengumpulan Data}

Pengumpulan data pada penelitian ini menggunakan data sekunder yang merupakan data yang didapat dari hasil penelitian sebelumnya. Data sekunder yang digunakan berasal dari hasil penelitian berikut ini:

1. Hudallah Muhammad Fauzi (2011) melakukan penelitian dengan judul "Durabilitas Beton yang Mengandung Fly Ash untuk Perkerasan Kaku (Rigid Pavement) yang Tahan terhadap Air Laut". Pada pengujian ini, kebutuhan faktor air-semen yang digunakan yaitu sebesar 0,45. Kebutuhan bahan campuran beton tertera pada Tabel 4.

Tabel 4. Kebutuhan Bahan Beto
\begin{tabular}{cc}
\hline Bahan & Komposisi \\
\hline Air [liter] & 19,25 \\
\hline Semen $[\mathrm{kg}]$ & 42,6 \\
\hline $\boldsymbol{w} / \boldsymbol{c}$ & 0,45 \\
\hline Pasir $[\mathrm{kg}]$ & 52,5 \\
\hline Kerikil $[\mathrm{kg}]$ & 78,75 \\
\hline
\end{tabular}

(Sumber: Fauzi, H. M., 2011)

2. Shamsad Ahmad, Abul Kalam Azad, dan Kevin F. Loughlin (2012) melakukan penelitian dengan judul "Effect of the Key Mixture Parameters on Tortuosity and Permeability of Concrete". Pada pengujian ini, faktor air-semen yang digunakan sebesar 0,4; 0,5; dan 0,6. Air pencampur yang digunakan yaitu air tawar. Adapun curing yang dilakukan yaitu menggunakan air tawar. Adapun data yang diperoleh yaitu mix design dengan variasi faktor air semen disajikan pada Tabel 5.

Tabel 5. Campuran Beton dengan Variasi Faktor Air Semen pada Air Tawar

\begin{tabular}{ccccc}
$\begin{array}{c}\text { No. } \\
\text { Mix }\end{array}$ & CA/FA Ratio & $\begin{array}{c}\text { Cement Content } \\
{\left[\mathbf{k g} / \mathbf{m}^{\mathbf{3}}\right]}\end{array}$ & $\mathbf{w / c}$ Ratio & $\begin{array}{c}\text { Mix Proportion } \\
\text { Cement : FA : CA }\end{array}$ \\
\hline 1 & 1,6 & 300 & 0,4 & $1: 2,67: 4,27$ \\
\hline 2 & 1,6 & 350 & 0,4 & $1: 2,21: 3,53$ \\
\hline 3 & 1,6 & 400 & 0,4 & $1: 1,87: 2,98$ \\
\hline 4 & 1,6 & 300 & 0,5 & $1: 2,63: 4,21$ \\
\hline 5 & 1,6 & 350 & 0,5 & $1: 2,17: 3,47$ \\
\hline 6 & 1,6 & 400 & 0,5 & $1: 1,83: 2,92$ \\
\hline 7 & 1,6 & 300 & 0,6 & $1: 2,59: 4,14$ \\
\hline 8 & 1,6 & 350 & 0,6 & $1: 2,13: 3,41$ \\
\hline 9 & 1,6 & 400 & 0,6 & $1: 1,79: 2,86$ \\
\hline
\end{tabular}

(Sumber: Ahmad, S., et al., 2012)

\subsection{Analisis Data}

Setelah terkumpul seluruh data yang dapat digunakan, selanjutnya yaitu melakukan analisis data. Adapun analisis data yang dilakukan adalah sebagai berikut:

1. Membuat grafik perbandingan porositas beton dengan perawatan direndam air tawar dan perawatan direndam air laut terhadap faktor air-semen pada beton.

2. Membuat grafik perbandingan permeabilitas pada beton dengan perawatan air tawar terhadap faktor air-semen pada beton.

3. Menganalisis grafik yang sudah dibuat.

4. Membandingkan hasil analisis grafik dengan perkiraan awal.

5. Menyimpulkan hasil penelitian. 


\section{PEMBAHASAN DAN PENGOLAHAN DATA}

Hasil uji kuat tekan dan porositas penelitian Fauzi, H. M. (2011), dapat dilihat pada Tabel 6.

Tabel 6. Hasil Pengujian Kuat Tekan dan Prorositas Beton Kondisi Rendaman Air Tawar dan Air Laut pada Umur 28 Hari

\begin{tabular}{ccc}
\hline \multirow{2}{*}{ Kondisi Rendaman } & \multicolumn{2}{c}{ Hasil Pengujian } \\
\cline { 2 - 3 } & $\begin{array}{c}\text { Kuat Tekan } \\
\text { [MPa] }\end{array}$ & $\begin{array}{c}\text { Porositas } \\
{[\%]}\end{array}$ \\
\hline Air Tawar & 35,65 & 17,79 \\
\hline Air Laut & 28,29 & 21,42 \\
\hline
\end{tabular}

Uji porositas beton pada Tabel 6 membuktikan bahwa porositas beton pada air laut lebih besar daripada porositas beton pada air tawar. Hal ini disebabkan karena air laut mengandung senyawa-senyawa kimia yang membuat beton mengembang sehingga porositasnya menjadi lebih besar. Jika porositas beton pada air laut bertambah besar maka hal ini akan menyebabkan permeabilitas juga membesar.

Jika hasil pengujian permeabilitas beton pada Tabel 6 disajikan dalam bentuk grafik, maka hasilnya diperlihatkan pada Gambar 3.

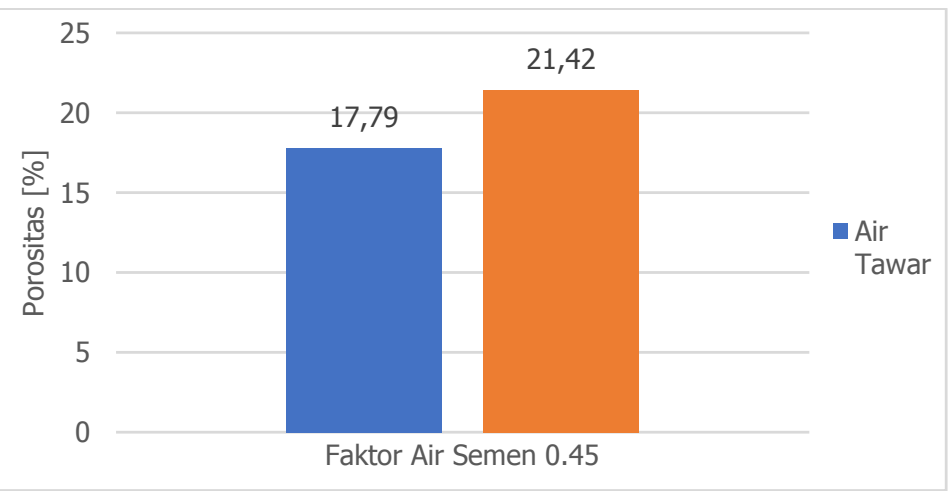

Gambar 3. Grafik hasil uji porositas pada beton dirawat dengan air tawar dan air laut

Selanjutnya hasil penelitian pada jurnal Ahmad, S., et al. (2012) disajikan pada Tabel 7.

Tabel 7. Hasil Pengujian Kuat Tekan dan Prorositas Beton Kondisi Rendaman Air Tawar dan Air Laut pada Umur 28 Hari

\begin{tabular}{ccc}
\hline \multirow{2}{*}{$\begin{array}{c}\text { No. } \\
\text { Mix }\end{array}$} & \multicolumn{2}{c}{ Hasil Pengujian } \\
\cline { 2 - 3 } & $\begin{array}{c}\text { Kuat Tekan } \\
{[\mathrm{MPa}]}\end{array}$ & $\begin{array}{c}\text { Permeabilitas } \\
{[\mathbf{m} / \mathbf{s}]}\end{array}$ \\
\hline 1 & 44,30 & $4,80 \times 10^{-12}$ \\
\hline 2 & 45,20 & $4,50 \times 10^{-12}$ \\
\hline 3 & 45,50 & $4,10 \times 10^{-12}$ \\
\hline 4 & 39,10 & $7,50 \times 10^{-12}$ \\
\hline 5 & 42,10 & $5,60 \times 10^{-12}$ \\
\hline 6 & 42,30 & $5,20 \times 10^{-12}$ \\
\hline 7 & 27,60 & $47,20 \times 10^{-12}$ \\
\hline 8 & 32,70 & $44,60 \times 10^{-12}$ \\
\hline 9 & 34,40 & $40,10 \times 10^{-12}$ \\
\hline
\end{tabular}


Jika campuran beton pada Tabel $\mathbf{7}$ diprediksi permeabilitasnya di lingkungan air laut menggunakan kajian perbandingan data yang tertera pada Tabel 6, diperkirakan nilai porositas berbanding lurus dengan nilai permeabilitas, maka nilai porositas meningkat sebesar 21,42/17,79; atau sebesar 1,204. Adapun hasil kajian perbandingan Tabel 6 disajikan dalam bentuk grafik terlihat pada Gambar 4, Gambar 5, dan Gambar 6.

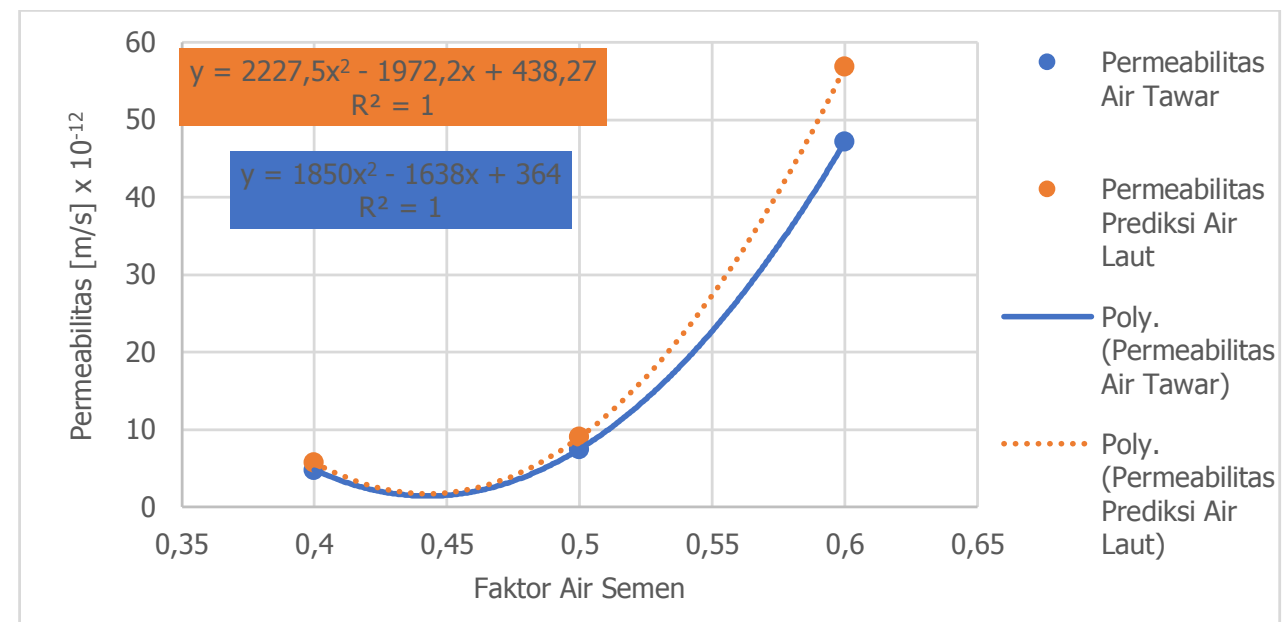

Gambar 4. Grafik hasil uji permeabilitas dengan kadar semen $300 \mathrm{~kg} / \mathrm{m}^{3}$

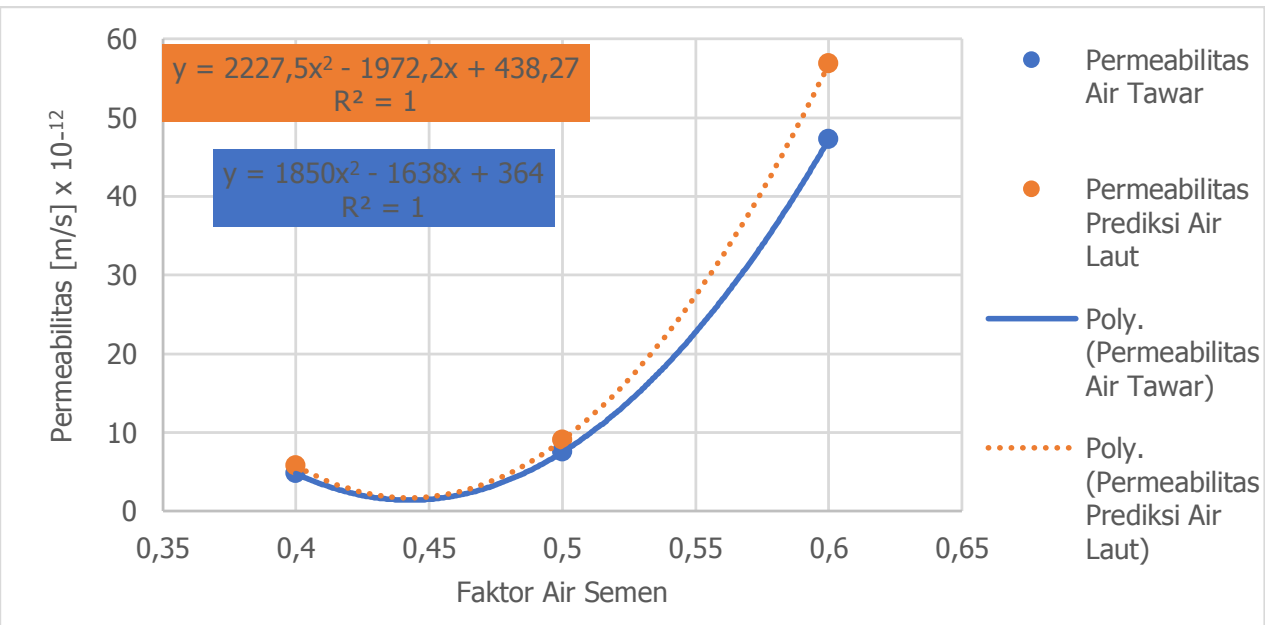

Gambar 5. Grafik hasil uji permeabilitas dengan kadar semen 350 kg/m ${ }^{3}$

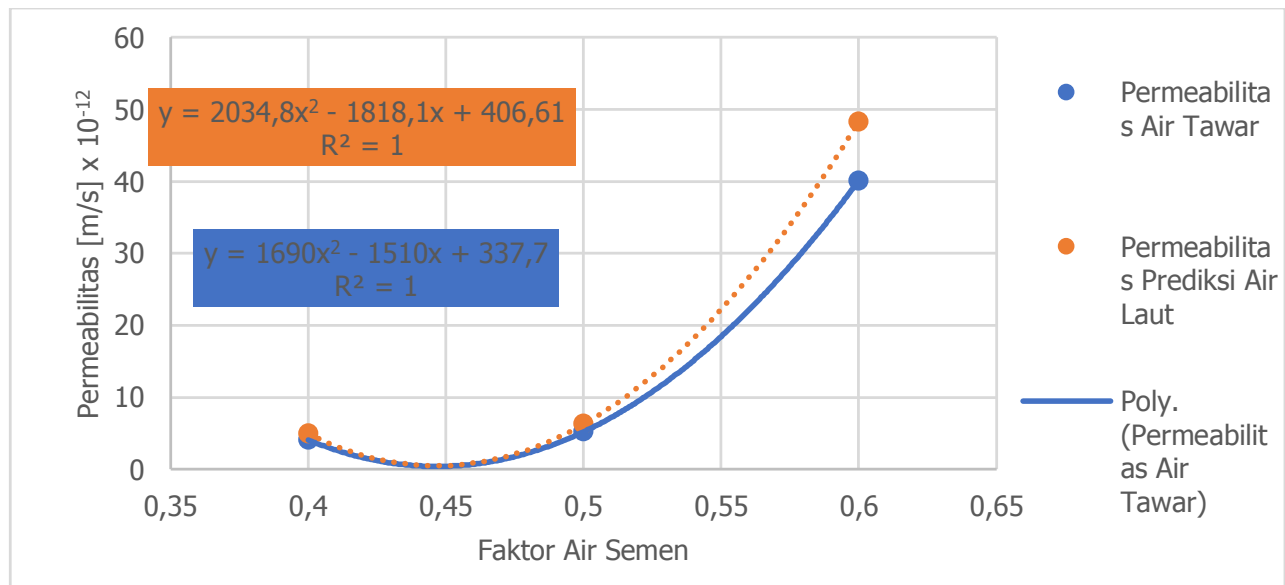

Gambar 6. Grafik hasil uji permeabilitas dengan kadar semen $400 \mathrm{~kg} / \mathrm{m}^{3}$ 
Uji permeabilitas beton membuktikan bahwa permeabilitas beton dipengaruhi baik faktor airsemen maupun kadar semen. Untuk kadar semen yang sama, semakin besar faktor air-semen akan menyebabkan permeabilitas beton meningkat. Hal ini disebabkan karena semakin tinggi nilai faktor air-semen maka semakin banyak jumlah air yang terkandung dalam beton. Apabila jumlah air semakin banyak, akan mengakibatkan semakin besarnya pori-pori beton sehingga porositas meningkat dan permeabilitas bertambah besar.

Permeabilitas beton terbesar pada air tawar untuk faktor air-semen 0,40-0,50 terjadi pada faktor air-semen 0,50 dengan kadar semen $300 \mathrm{~kg} / \mathrm{m}^{3}$, yaitu sebesar 7,50 x 10 $10^{-12} \mathrm{~m} / \mathrm{s}$. Sementara itu, untuk faktor air-semen 0,60; besarnya permeabilitas beton pada air tawar adalah $47,20 \times 10^{-12} \mathrm{~m} / \mathrm{s}$.

Jika permeabilitas beton pada air tawar untuk faktor air-semen 0,50 ini diprediksi besarnya pada air laut maka dengan asumsi bahwa permeabilitas berbanding lurus dengan porositas; besarnya permeabilitas beton pada air laut $(k)$ untuk faktor air-semen sebesar 0,50 dengan kadar semen $300 \mathrm{~kg} / \mathrm{m}^{3}$ adalah sebesar:

$$
\begin{gathered}
k=\frac{\text { porositas beton di air laut }}{\text { porositas beton di air tawar }} \times \text { permeabilitas di air tawar } \\
k=\frac{21,42 \%}{17,79 \%} \times\left(7,5 \times 10^{-12}\right)=9,03 \times 10^{-12} \mathrm{~m} / \mathrm{s}
\end{gathered}
$$

Dengan cara yang sama maka untuk faktor air-semen 0,6; permeabilitas beton di air laut menjadi:

$$
k=\frac{21,42 \%}{17,79 \%} \times\left(47,2 \times 10^{-12}\right)=56,83 \times 10^{-12} \mathrm{~m} / \mathrm{s}
$$

Jika tebal selimut beton $3 \mathrm{~cm}$ atau 0,03 m; maka waktu yang diperlukan air laut untuk melalui atau menembus selimut beton tersebut $(t)$ adalah:

$$
\begin{aligned}
& \text { Untuk } w / c \text { sebesar 0,5: } t=\frac{0,03 \mathrm{~m}}{9,03 \times 10^{-12} \mathrm{~m} / \mathrm{s}}=3.322 .259 .136 \mathrm{~s}=105 \text { tahun } \\
& \text { Untuk } w / c \text { sebesar 0,6: } t=\frac{0,03 \mathrm{~m}}{56,83 \times 10^{-12} \mathrm{~m} / \mathrm{s}}=527.890 .198,8 \mathrm{~s}=16 \text { tahun }
\end{aligned}
$$

Pada umumnya umur bangunan dirancang untuk masa 50 tahun. Berdasarkan perhitungan waktu yang diperlukan untuk melalui selimut beton ini maka faktor air-semen sebesar 0,50 masih mampu mendukung ketahanan beton untuk umur bangunan 50 tahun. Jika faktor airsemen sebesar 0,45 maka umur beton akan melebihi umur beton pada faktor air-semen sebesar 0,50 disebabkan permeabilitas beton menjadi semakin kecil.

\section{KESIMPULAN DAN SARAN}

\subsection{Kesimpulan}

Berdasarkan hasil pembahasan penelitian ini, maka dapat disimpulkan:

1. Batasan faktor air-semen sebesar 0,45 pada cara SNI 03-2384-2000 untuk beton yang terendam air laut merupakan batasan yang sangat aman.

2. Batasan faktor air-semen sebesar 0,45 pada cara SNI 03-2384-2000 masih dapat diperbesar sampai dengan sebesar 0,50 dengan syarat kadar semen minimal sebesar 300 
$\mathrm{kg} / \mathrm{m}^{3}$ karena masih mampu mendukung ketahanan (durabilitas) beton yang dinyatakan dalam umur bangunan.

\subsection{Saran}

Adapun saran-saran yang dapat dilakukan untuk penelitian selanjutnya yaitu hasil uji permeabilitas dan kuat tekan beton harus dilanjutkan dengan pengujian di laboratorium.

\section{DAFTAR RUJUKAN}

Ahmad, S., Azad, A. K., \& Loughlin, K. F. (2012). Effect of the Key Mixture Parameters on Tortuosity and Permeability of Concrete. Journal of Advanced Concrete Technology, 10(3), 86-94.

Badan Standardisasi Nasional. (2000). SNI 03-2834-2000 tentang Tata Cara Pembuatan Rencana Campuran Beton Normal. Jakarta: Badan Standardisasi Nasional.

Emmanuel, A. O., Oladipor, F. A., \& Olabode, O. (2012). Investigation of Salinity Effect on Compressive Strength of Reinforced Concrete. Journal of Sustainable Development, 5(6), 74-82.

Fauzi, H. M. (2017). Durabilitas Beton yang Mengandung Fly Ash untuk Perkerasan Kaku (Rigid Pavement) yang Tahan terhadap Air Laut. Tugas Akhir. Surakarta: Jurusan Teknik Sipil - Universitas Sebelas Maret.

Tjokrodimuljo, K. (2007). Teknologi Beton. Yogyakarta: Biro Penerbit Teknik Sipil Universitas Gadjah Mada.

Wedhanto, S. (2017). Pengaruh Air Laut terhadap Kekuatan Tekan Beton yang Terbuat dari Berbagai Merk Semen yang Ada di Kota Malang. Jurnal Bangunan, 22(2), 21-30.

Zhao, Y., Wittman, F. H., Zhang, P., Wang, P. G., \& Zhao, T. J. (2014). Penetration of Water and Chloride Dissolved in Water into Concrete under Hydraulic Pressure. Restoration of Buildings and Monuments, 20(2), 117-126. 